\title{
Production of neoagarooligosaccharides by probiotic yeast Saccharomyces cerevisiae var. boulardii engineered as a microbial cell factory
}

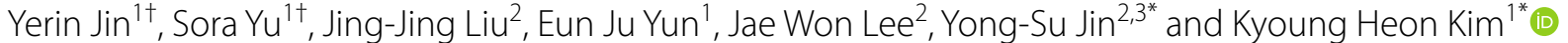

\begin{abstract}
Background: Saccharomyces cerevisiae var. boulardii is a representative probiotic yeast that has been widely used in the food and pharmaceutical industries. However, S. boulardii has not been studied as a microbial cell factory for producing useful substances. Agarose, a major component of red macroalgae, can be depolymerized into neoagarooligosaccharides (NAOSs) by an endo-type $\beta$-agarase. NAOSs, including neoagarotetraose (NeoDP4), are known to be health-benefiting substances owing to their prebiotic effect. Thus, NAOS production in the gut is required. In this study, the probiotic yeast $S$. boulardii was engineered to produce NAOSs by expressing an endo-type $\beta$-agarase, BpGH16A, derived from a human gut bacterium Bacteroides plebeius.

Results: In total, four different signal peptides were compared in S. boulardii for protein (BpGH16A) secretion for the first time. The SED1 signal peptide derived from Saccharomyces cerevisiae was selected as optimal for extracellular production of NeoDP4 from agarose. Expression of BpGH16A was performed in two ways using the plasmid vector system and the clustered regularly interspaced short palindromic repeat (CRISPR)-Cas9 system. The production of NeoDP4 by engineered S. boulardii was verified and quantified. NeoDP4 was produced by S. boulardii engineered using the plasmid vector system and CRISPR-Cas9 at 1.86 and $0.80 \mathrm{~g} / \mathrm{L}$ in a 72-h fermentation, respectively.
\end{abstract}

Conclusions: This is the first report on NAOS production using the probiotic yeast S. boulardii. Our results suggest that $S$. boulardii can be considered a microbial cell factory to produce health-beneficial substances in the human gut.

Keywords: BpGH16A, Saccharomyces boulardii, CRISPR-Cas9, Neoagarooligosaccharides, Probiotics, Prebiotics

\section{Background}

The gut microbiota and intestinal immunity have been found to have a major impact on human health $[1,2]$. Microbial cell factories, including Saccharomyces cerevisiae, have been approved for human use and have been developed to produce therapeutic proteins [3, 4]. Thus, if a microbial cell factory that can directly

\footnotetext{
*Correspondence: ysjin@illinois.edu; khekim@korea.ac.kr

${ }^{\dagger}$ Yerin Jin and Sora Yu contributed equally to this work

1 Department of Biotechnology, Graduate School, Korea University, Seoul 02841, South Korea

${ }^{2}$ Carl R. Woese Institute for Genomic Biology, University of Illinois at Urbana-Champaign, Urbana, IL 61801, USA

Full list of author information is available at the end of the article
}

produce therapeutic proteins in the intestine is developed, it would be possible to study the effects of intestinal microbes on health more accurately, and the microbial cell factory could be used for the treatment of actual diseases. When designing microbial cell factories, one important consideration is the selection of an appropriate microbial host as an expression system [5], based on its safety and health benefits. Therefore, well-known probiotics, such as lactic acid bacteria and Saccharomyces cerevisiae var. boulardii, could be promising hosts as expression systems.

Lactic acid bacteria or intestinal bacteria can be used as hosts for microbial cell factories, but there may be some constraints. First, from a pharmacokinetic point of view, 
it may be necessary to control the inhabiting population and residence time in the gut [6]. In the case of S. boular$d i i$, this yeast was washed out in the gut within 3-5 days after discontinuing oral administration $[7,8]$. However, in the case of intestinal bacteria, it is not possible to control their inhabiting population and residence time in the gut. Second, post-translational modifications including glycosylation and phosphorylation of eukaryotic proteins, are crucial for the expression of their biological activity [9]. Therefore, yeast has been used as an eukaryotic host to produce many therapeutic proteins [9]. Taken together, the eukaryotic probiotic $S$. boulardii is considered a promising host to use as an intestinal microbial cell factory $[10,11]$.

S. boulardii, originally isolated from lychee and mangosteen, is a generally recognized as safe (GRAS) yeast $[12,13]$. S. boulardii is known to survive in the human gastrointestinal tract owing to its high tolerance to low $\mathrm{pH}$ and high temperatures [13, 14]. Additionally, S. boulardii is the only probiotic yeast found to be effective in double-blind studies $[14,15]$. Previously, the metabolic engineering of $S$. boulardii and its use as a potential oral vaccine delivery vehicle were studied in mouse models $[16,17]$. However, to our knowledge, there have been no studies yet on the production of prebiotics which possess a beneficial effect on the health of a host by selective stimulation of the activity or growth of probiotic-like bacteria in the colon using an engineered $S$. boulardii [18]. In this study, we engineered the probiotic yeast $S$. boulardii to produce bioactive substances with prebiotic effects with the ultimate goal of developing a synbiotic system for humans.

When non-digestible diets reach the large intestine, they are utilized by the gut microbiota. Subsequently, non-digestible diets change the intestinal microflora and affect the overall health of the host $[19,20]$. As a non-digestible diet, agarose, a polysaccharide obtained from red macroalgae, is commonly used as dietary fiber by East Asians [21]. Neoagarooligosaccharides (NAOSs) derived from agarose were found to have various physiological and biological activities, including anti-obesity, anti-diabetic, anti-inflammatory, anti-viral, and antitumor activities [22-27]. Moreover, in vivo experiments confirmed that NAOSs have a prebiotic effect [28]. In particular, neoagarotetraose (NeoDP4), which contains various bioactive properties, such as anti-inflammatory [29] and anti-oxidative activity [30], has been found to be a potential prebiotic for modulating intestinal microbiota, thereby promoting the health of the host. In addition, Bifidobacterium, which is considered as a beneficial probiotic microorganism having therapeutic benefits and is one of the most commonly used probiotics in humans [31], significantly increased in mice treated with antibiotics supplemented with NeoDP4 [29]. NeoDP4 can be produced by endo-type $\beta$-agarase from agarose. Recently, an endo-type $\beta$-agarase, $B p \mathrm{GH} 16 \mathrm{~A}$ originating from human gut bacterium Bacteroides plebeius, has been reported [32, 33]. As B. plebeius was isolated from human gut microbes that can be considered relatively safe, BpGH16A was chosen to be expressed in S. boulardii to enzymatically produce NAOSs, primarily NeoDP4, from agarose.

In this study, we introduced and expressed the gene for $B p \mathrm{GH} 16 \mathrm{~A}$ in the probiotic yeast $S$. boulardii using CRISPR-Cas9, and the production of prebiotic NeoDP4 from agarose by the engineered $S$. boulardii was verified and optimized (Fig. 1). To our knowledge, this is the first study to show that the probiotic $S$. boulardii can be used as a microbial cell factory for producing prebiotics.

\section{Methods}

\section{Strains and media}

Escherichia coli $\mathrm{DH} 5 \alpha$ was used to construct the plasmids. E. coli strains were grown in Luria-Bertani medium (10 g/L tryptone, $5 \mathrm{~g} / \mathrm{L}$ yeast extract, and $10 \mathrm{~g} / \mathrm{L}$ sodium chloride) containing $100 \mu \mathrm{g} / \mathrm{mL}$ ampicillin (SigmaAldrich, St. Louis, MO, USA) at $37^{\circ} \mathrm{C}$ and $200 \mathrm{rpm}$. $S$. boulardii ATCC MYA-796 was used as the parental strain for producing NeoDP4. Yeast strains were grown at $37{ }^{\circ} \mathrm{C}$ on yeast synthetic complete (YSC) medium, which contained a $6.7 \mathrm{~g} / \mathrm{L}$ yeast nitrogen base without amino acids (Becton, Dickinson and Company, Franklin Lakes, NJ, USA), $20 \mathrm{~g} / \mathrm{L}$ glucose, and $1.92 \mathrm{~g} / \mathrm{L}$ yeast synthetic drop-out medium supplements without uracil (Sigma-Aldrich), or YSC medium, which contained a $6.7 \mathrm{~g} / \mathrm{L}$ yeast nitrogen base (Becton, Dickinson and Company) and $20 \mathrm{~g} / \mathrm{L}$ glucose. For CRISPR-Cas9-based genome editing experiments, $100 \mu \mathrm{g} / \mathrm{mL}$ nourseothricin (NAT; Jena Bioscience, Jena, Germany) and $500 \mu \mathrm{g} /$ $\mathrm{mL}$ geneticin (AG Scientific, San Diego, CA, USA) were added to the medium if required for selection of the transformants.

\section{Plasmid and strain construction}

To use the auxotrophic marker for transformant selection, a strain with inactivated HIS3, TRP1, and URA3 was created first. Based on the SB-TU strain [17] in which TRP1 and URA3 were inactivated, HIS3 was further inactivated. The gene fragment of HIS3 [34] was amplified using the primer pair gHIS3_F and gHIS3_R (Table 1). The resulting polymerase chain reaction (PCR) product was digested with SacI and NotI and ligated to pRS42H, resulting in plasmid p42H_gHIS3, designed for simultaneously inactivating HIS3 (Table 2). Repair DNA for HIS3 disruption was amplified using PCR by using primers dDNA_HIS3_F and dDNA_HIS3_R (Table 1). 


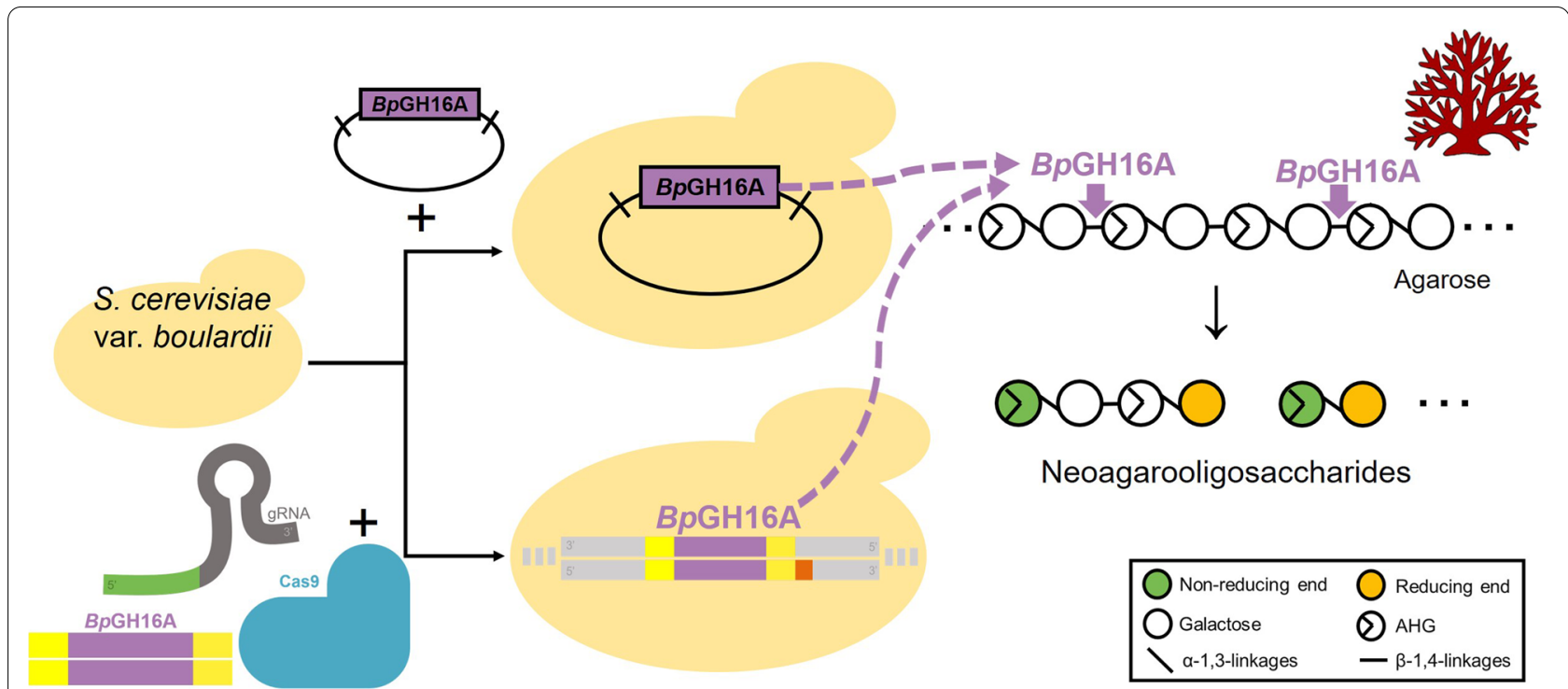

Fig. 1 Schematic representation of NAOS production by engineered S. boulardii. BpGH16A expression was performed using two different systems. The first was a vector system with an auxotrophic marker, and the second was the clustered regularly interspaced short palindromic repeat (CRISPR)-Cas9 system. NAOSs, neoagarooligosaccharides; BpGH16A, endo-type $\beta$-agarase originating from human gut bacterium Bacteroides plebeius

The Cas9-NAT plasmid conferring NAT resistance was used to select the transformants using an antibiotic marker after transformation [34]. Yeast transformation into SB-TU was carried out using the polyethyleneglycol (PEG)-LiAc method, as described previously [35]. Finally, $S$. boulardii strain SB-HTU, in which HIS3, TRP1, and URA3 were inactivated, was constructed (Table 3 ).

Plasmids that were used to screen an optimal signal peptide for secretion of $B p \mathrm{GH} 16 \mathrm{~A}$ were constructed as follows. The gene BACPLE_01670, encoding BpGH16A, was cloned into the pRS426GPD plasmid. The BpGH16A gene fragment was amplified from B. plebeius DSM 17135 (DSMZ, Braunschweig, Germany) genomic DNA using PCR with different primer pairs depending on the type of signal peptide (Table 1 ). The predicted signal peptide sequences at the $\mathrm{N}$-terminus of $\mathrm{Bp} \mathrm{GH} 16 \mathrm{~A}$ were removed for signal peptide screening. In total, four different signal peptides, namely chicken lysozyme signal peptide (CL), $\alpha$-mating factor signal peptide $(\alpha-M F)$ from S. cerevisiae, Sta1 signal peptide (STA1) from Saccharomyces diastaticus, and Sed1 signal peptide (SED1) from $S$. cerevisiae, were used $[17,36,37]$. Additionally, for construction of the control strain without any signal peptide, PCR was performed using the primer pairs 16A_W/OSP_F_SpeI and 16A_W/OSP_R_XhoI (Table 1). The PCR products were double-digested by restriction enzymes determined during primer design and ligated with plasmid pRS426GPD digested using the same restriction enzymes, using T4 DNA ligase (New
England Biolabs, Ipswich, MA, USA). The resulting plasmids were designated as $\mathrm{p} 426 \_B \mathrm{Bp} \_$W/OSP, p426_Bp_CL, p426_Bp_ $\alpha M F, \quad$ p426_Bp_STA1, and p426_Bp_SED1 (Table 2). Yeast transformation into SB-HTU was performed using the PEG-LiAc method. Finally, the experimental strains SB-HTU_16A_C, SB-HTU_16A_A, SB-HTU_16A_S, and SB-HTU_16A_D were prepared for signal peptide screening (Table 3). As control strains, SBHTU_E harboring neither BpGH16A nor signal peptide, and only pRS426GPD vector, and SB-HTU_W harboring the $B p$ GH16A gene but no signal peptide were prepared.

To integrate the BpGH16A gene into the genome of $S$. boulardii for the stable expression of $B p$ GH16A, a guide RNA plasmid p42K_CS5 was constructed (Table 2). The plasmid was generated using reverse PCR of the pRS42K plasmid containing a guide RNA sequence using the primer pairs gRNA_CS5_F and gRNA_CS5_R (Table 1). The 20-bp targeting sequence of the guide RNA binds to the front of the PAM sequence (NGG) in the empty locus on chromosome XV (CS5). The BpGH16A and SED1 signal peptide were incorporated into this locus via homologous recombination without affecting the function of other genes. For homologous recombination, the plasmid p426_Bp_SED1 was amplified using the primer pairs dDNA-CS5-F and dDNA-CS5-R as donor DNA for genome integration using CRISPR-Cas9 (Table 1). To overcome the inefficiencies associated with genome integration, the PCR product constructed using the primer pairs dDNA-CS5-F and dDNA-CS5-R was amplified using PCR by using primer 
Table 1 Primers used in this study

\begin{tabular}{|c|c|}
\hline Primer & Sequence $\left(5^{\prime} \rightarrow 3^{\prime}\right.$, restriction sites are underlined) \\
\hline gHIS3_F & TCCACCTAGCGGATGACTCT \\
\hline gHIS3_R & TGCATTACCTTGTCATCTTC \\
\hline dDNA_HIS3_F & GTAAAGCGTATTACAAATGAAACCAAGATTCAGATTGCGATCTCTTTAAAGGGTTAACCC \\
\hline dDNA_HIS3_R & TTCTGGGAAGATCGAGTGCTCTATCGCTAGGGGTTAACCCTTTAAAGAGATCGCAATCTG \\
\hline 16A_W/OSP_F_Spel & ATA $\underline{\text { ACT AGT GCA GAA AAT TTA AAT AAT AAA TCA TAC GAG TG }}$ \\
\hline 16A_W/OSP_R_Xhol & 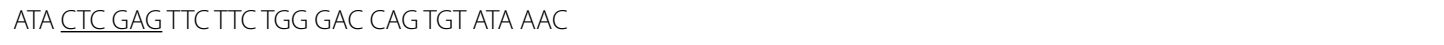 \\
\hline 16A_CL_F_Spel & $\begin{array}{l}\text { ATA ACT AGT ATG AGG TCTTTG CTA ATC TTG GTG CTTTGC TTC CTG CCC CTG GCT GCT CTG GGG GCA GAA AAT TTA AAT AAT } \\
\text { AAA TCA TAC }\end{array}$ \\
\hline 16A_CL_R_Xhol & ATA CTC GAG TTC TTC TGG GAC CAG T \\
\hline aMF_F_Spel & ATA $\underline{\text { ACT AGT ATG AGA TTT CCT TCA ATTTTT ACT G }}$ \\
\hline aMF_R_16A & GCA GAA AAT TTA AAT AAT AAA GCTTCA GCC TCT CTT TTC T \\
\hline 16A_F_aMF & GAG AAA AGA GAG GCT GAA GCT GCA GAA AAT TTA AAT AAT AAA TCA TAC G \\
\hline 16A_R_aMF_BamHI & ATA GGA TCC TTC TTC TGG GAC CAG TGT AT \\
\hline STA1_F_EcoRI & ATA GAA TTC ATG GTA GGC CTC AAA AAT C \\
\hline STA1_16A_R & GCA GAA AATTTA AAT AAT AAA TCA TAC GAG TTTTTT CTG TCG CTG GAG C \\
\hline 16A_STA1_F & GGC TCC AGC GAC AGA AAA AAG CAG AAA ATTTAA ATA ATA AAT CAT ACG AG \\
\hline 16A_R_Xhol & 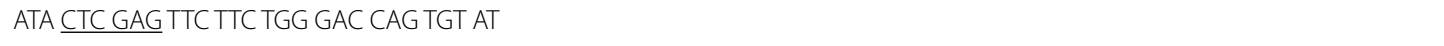 \\
\hline 16A_SED1_F_Spel & $\begin{array}{l}\text { ATA ACT AGT ATG AAA TTA TCA ACT GTC CTA TTA TCT GCC GGT TTA GCC TCG ACT ACT TTG GCC CAA GCA GAA AAT TTA AAT AAT } \\
\text { AAA TCA }\end{array}$ \\
\hline 16A_SED1_R_Xhol & 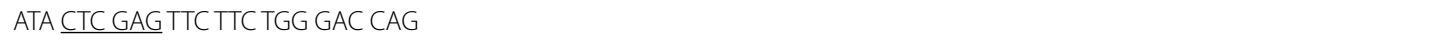 \\
\hline dDNA-CS5-F & AAA AGA GAA GAA AAA AGA GAA GAA ATG AATTCT ATT ATG ATA GCG AAT GCA ATT AAC CCT CAC TAA AGG GA \\
\hline dDNA-CS5-R & TGC TGG TTG CCT TAT TAA TTT ATA TGG AAG ACG AGA TAA TTC ATT AAT TAG TAA TAC GAC TCA CTA TAG GGC \\
\hline dDNA-CS5 +60_F & $\begin{array}{l}\text { ATG GTA CAC GCT CTT GGC AAC ATT GAA ATT ACA GCT CTC ATA TAT AAA AAA TGG AAA GAA AAA AGA GAA GAA AAA AGA GAA } \\
\text { GAA ATG AAT }\end{array}$ \\
\hline dDNA-CS5+60_R & $\begin{array}{l}\text { GGC ATA ACA ATA GCG CAC AGA TCC GCA GGT TTC GTA ATA CGC TTA ACA ATA GGC GTC TCC TGC TGG TTG CCT TAT TAA TTT ATA } \\
\text { TGG AAG }\end{array}$ \\
\hline gCS5_F & CTG GTA GTT GCA CAG AAA GAG TTT TAG AGC TAG AAA TAG CAA G \\
\hline gCS5_R & TCTTTC TGT GCA ACT ACC AGC GAT CAT TTA TCTTTC ACT GCG \\
\hline Conf-CS5-F & AAT GAA TTC TAT TAT GAT AGC GAA TGC \\
\hline Conf-CS5-R & CAC AGG ATTTAC GAA GAC C \\
\hline
\end{tabular}

Table 2 Plasmids used in this study

\begin{tabular}{|c|c|c|}
\hline Plasmid & Description & References \\
\hline pRS42H & $2 \mu$ origin & EUROSCARF \\
\hline p42H_gHIS3 & pRS42H carrying HIS3 disruption gRNA cassette & This study \\
\hline pRS426GPD & URA3, GPD promoter, CYC1 terminator, $2 \mu$ origin, and Amp & Mumberg et al. [45] \\
\hline p426_Bp_W/OSP & pRS426GPD harboring BpGH16A from B. plebeius, deletion signal peptide & This study \\
\hline p426_Bp_CL & pRS426GPD harboring BpGH16A and chicken lysozyme signal peptide & This study \\
\hline p426_Bp_aMF & pRS426GPD harboring BpGH16A and a-mating factor signal peptide & This study \\
\hline p426_Bp_STA1 & pRS426GPD harboring BpGH16A and STA1 signal peptide & This study \\
\hline p426_Bp_SED1 & pRS426GPD harboring BpGH16A and SED1 signal peptide & This study \\
\hline Cas9-NAT & p414-TEF1p-Cas9-CYC1t-NAT1 & Zhang et al. [34] \\
\hline pRS42K & $2 \mu$ origin, KanMX & Taxis and Knop [46] \\
\hline p42K_CS5 & pRS42K, gRNA cassette targeting the intergenic site on Chr XV & This study \\
\hline 16 A-D-CS5 & BpGH16A, SED1 signal peptide, donor DNA for CS5 site integration & This study \\
\hline
\end{tabular}


Table 3 Strains used in this study

\begin{tabular}{lll}
\hline Strain & Description & References \\
\hline S. boulardii & ATCC MYA-796 & ATCC \\
SB-TU & S. boulardii; TRP1 and URA3 disruption & Liu et al. [17] \\
SB-HTU & S. boulardii; HIS3, TRP1, and URA3 disruption & This study \\
SB-HTU_16A_E & SB-HTU; pRS426GPD & This study \\
SB-HTU_16A_W & SB-HTU; BPGH16A, deletion signal peptide, pRS426GPD & This study \\
SB-HTU_16A_C & SB-HTU; BpGH16A, chicken lysozyme signal peptide, pRS426GPD & This study \\
SB-HTU_16A_A & SB-HTU; BpGH16A, a-mating factor signal peptide, pRS426GPD & This study \\
SB-HTU_16A_S & SB-HTU; BPGH16A, STA1 signal peptide, pRS426GPD & This study \\
SB-HTU_16A_D & SB-HTU; BPGH16A, SED1 signal peptide, pRS426GPD & This study \\
SB_16A_D & S.boulardii; BPGH16A, SED1 signal peptide & This study \\
\hline
\end{tabular}

pairs CS5+60_F and CS5+60_R (Table 1). The homologous region was found to be approximately $120 \mathrm{bp}$. During yeast transformation, $1 \mu \mathrm{g}$ of Cas9-NAT plasmid, $20 \mu \mathrm{g}$ of 16 A-D-CS5 with donor DNA, and $2 \mu \mathrm{g}$ of p42K_CS5 with guide RNA were added to $S$. boulardii and transformed. Genomic integration was verified with yeast colony PCR by using the primer pairs Conf-CS5-F and Conf-CS5-R (Table 1).

\section{Fermentation experiments}

To produce NAOSs in the engineered $S$. boulardii, fermentation was performed with $2.5 \mathrm{~g} / \mathrm{L}$ agarose at $37{ }^{\circ} \mathrm{C}$ and $200 \mathrm{rpm}$ in 125-mL flasks for $72 \mathrm{~h}$. During fermentation, agarose, low gelling temperature (Sigma-Aldrich) was used to prevent congealing of agarose. First, strains SB-HTU_16A_C, SB-HTU_16A_A, SB-HTU_16A_S, and SB-HTU_16A_D were grown in YSC medium at $37{ }^{\circ} \mathrm{C}$ and $200 \mathrm{rpm}$. Pre-cultured cells were centrifuged at 10,170 $\times g$ for $10 \mathrm{~min}$ and washed twice using sterilized distilled water. The harvested cells were inoculated into $20 \mathrm{~mL}$ of YSC medium containing $20 \mathrm{~g} / \mathrm{L}$ glucose and $2.5 \mathrm{~g} / \mathrm{L}$ agarose in $50 \mathrm{mM}$ potassium hydrogen phthalate (KHP) buffer ( $\mathrm{pH}$ 5.5). The initial cell density was adjusted to an optical density at $600 \mathrm{~nm}\left(\mathrm{OD}_{600}\right)$ of 1.0. As a control, strains SBHTU_16A_E and SB-HTU_16A_W were fermented under the same conditions.

To examine NAOSs production by $S$. boulardii SB_16A_D engineered by CRISPR-Cas9, fermentation was performed in YSC medium. Pre-cultured cells in YSC medium were inoculated in $20 \mathrm{~mL}$ of YSC medium containing $20 \mathrm{~g} / \mathrm{L}$ glucose and $2.5 \mathrm{~g} / \mathrm{L}$ agarose in $50 \mathrm{mM} \mathrm{KHP}$ buffer $(\mathrm{pH} 5.5)$. The initial cell density was adjusted to $\mathrm{OD}_{600}=1.0$. Wild-type $S$. boulardii ATCC MYA-796 was used as the control strain. Fermentation experiments were performed in triplicates.

\section{Analyses of cell growth and NAOS production using high-performance liquid chromatography}

Cell growth was monitored by measuring $\mathrm{OD}_{600}$ using a UV-visible spectrophotometer (Bio-Rad, Hercules, CA, USA). To analyze and quantify the reaction products of agarose by the engineered $S$. boulardii, including NeoDP4, glucose, acetic acid, and ethanol, high-performance liquid chromatography (HPLC) analysis was performed. The HPLC system (Agilent Technologies, Santa Clara, CA, USA) was equipped with a refractive index (RI) detector (Agilent Technologies) using an Aminex HPX-87H column (Bio-Rad). The column and RI detector temperatures were set to 65 and $55{ }^{\circ} \mathrm{C}$, respectively, and the column was eluted with $0.005 \mathrm{M}$ $\mathrm{H}_{2} \mathrm{SO}_{4}$ at a flow rate of $0.5 \mathrm{~mL} / \mathrm{min}$.

\section{Identification of NAOSs using thin-layer chromatography} To identify the hydrolyzed products of agarose during fermentation, thin-layer chromatography (TLC) analysis was performed. During fermentation, $1 \mathrm{~mL}$ of cell culture containing the fermentation products was obtained for each time point $(0,12,24,36,48$, and $72 \mathrm{~h}$ ). For accurate measurements, the obtained cell culture was boiled to terminate the possible enzymatic reaction. After centrifugation at $16,609 \times g$ for $15 \mathrm{~min}$ at $4{ }^{\circ} \mathrm{C}$, a $1-\mu \mathrm{L}$ aliquot from each supernatant was loaded onto silica gel 60 plates (Merck, Damstadt, Germany). After drying the TLC plates, they were visualized with $10 \%(\mathrm{v} / \mathrm{v}) \mathrm{H}_{2} \mathrm{SO}_{4}$ in ethanol and $0.2 \%(\mathrm{w} / \mathrm{v})$ naphthoresorcinol in ethanol, as previously described [38].

\section{Results}

\section{NeoDP4 production by engineered yeast}

To produce NeoDP4 by engineered yeast, $\beta$-agarase secretion from yeast was necessary for agarose degradation. Therefore, the expression and secretion of an endotype $\beta$-agarase, $B p$ GH16A, by yeast $S$. boulardii, was tested first. To confirm that $B p G H 16 A$ is functionally 
expressed and secreted by S. boulardii, SB-HTU_16A_C containing $\mathrm{CL}$, which has been previously proven to work in S. boulardii, was used [17].

In the HPLC analysis of SB-HTU_16A_C fermentation products, a significant peak at an approximate retention time of $7.6 \mathrm{~min}$, corresponding to NeoDP4, was detected in the sample (Fig. 2). In contrast, no peak was detected in the sample from the control strain, SB-HTU_16A_E, harboring the empty vector. Thus, these results showed that $B p \mathrm{GH} 16 \mathrm{~A}$ was functionally expressed, secreted from $S$. boulardii, and produced NeoDP4 by hydrolyzing agarose.

\section{Screening of the optimal signal peptide for NeoDP4 production by S. boulardii}

As the enzyme $B p \mathrm{GH} 16 \mathrm{~A}$ was confirmed to be functionally expressed and secreted by $S$. boulardii, the next

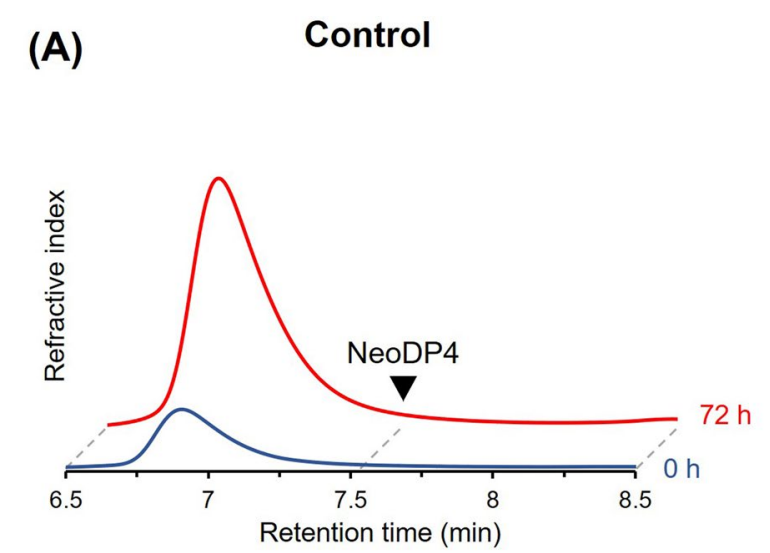

(B) Engineered S. cerevisiae var. boulardii

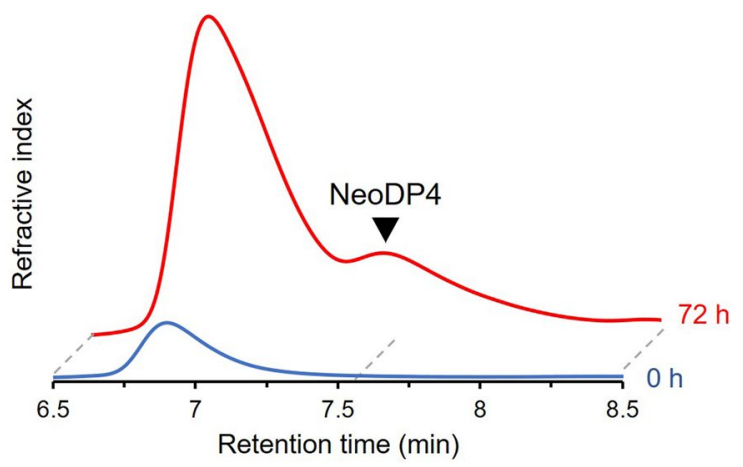

Fig. 2 Identification of NeoDP4 produced via fermentation by the engineered yeast S. boulardii SB-HTU_16A_C strain using HPLC. HPLC chromatograms of (A) control and (B) engineered S. boulardii SB-HTU_16A_C strains at $72 \mathrm{~h}$ of fermentation. The peak of NeoDP4 showed a retention time approximately at $7.6 \mathrm{~min}$. Control, SB-HTU_16A_E harboring the empty plasmid pRS426GPD; the engineered S. boulardii, SB-HTU_16A_C harboring p426_Bp_CL; NeoDP4, neoagarotetraose step was to identify the optimal signal peptide to further increase NeoDP4 production. Four different signal peptides, CL, $\alpha$-MF, STA1, and SED1, were tested. Each signal peptide was individually pre-fixed to the $B p \mathrm{GH} 16 \mathrm{~A}$ sequences and introduced into SB-HTU to identify the signal peptide that produces more NeoDP4. Production of NeoDP4 by the engineered yeasts was verified using TLC analysis at $72 \mathrm{~h}$ (Fig. 3A); NeoDP4 was strongly produced by the strains containing CL and SED1. The NeoDP4 spot was weakly detected by the strain with $\alpha$-MF. To compare the amount of NeoDP4 produced by each engineered yeast more accurately, HPLC analysis was performed (Fig. 3B). NeoDP4 was found to have gradually increased during the 72 -h fermentation by each strain, and the highest amount of NeoDP4 was produced by the strain containing SED1. The amount of NeoDP4 produced after $72 \mathrm{~h}$ of fermentation was 1.73, 0.95, 0.99, and $1.86 \mathrm{~g} / \mathrm{L}$ when signal peptides, namely $\mathrm{CL}, \alpha-\mathrm{MF}$, STA1, and SED1, respectively, were used. The production of NeoDP4 by the strain containing SED1 was 1.08, 1.96, and 1.88 times higher than that by the strains containing CL, $\alpha-M F$, and STA1, respectively. Thus, SED1 from $S$. cerevisiae, which showed the highest production of NeoDP4, was selected for further NeoDP4 production.

Meanwhile, NeoDP4 was not produced in any control group, whereas it was produced in all groups in which the signal peptide was present (Fig. 3). In particular, SBHTU_16A_W, which was used as a negative control, was constructed to confirm that the extracellular activity of $B p \mathrm{GH} 16 \mathrm{~A}$ was not derived from cell lysis but from secretion due to the heterologously expressed signal peptides. As NeoDP4 was not detected in the culture broth of SBHTU_16A_W, the degradation of agarose into NeoDP4 was confirmed to be caused by the secreted BpGH16A.

\section{Fermentation for the production of NeoDP4 by the engineered yeast}

Based on the signal peptide screening results, the strain SB-HTU_16A_D containing the SED1 signal peptide was fermented in YSC medium without uracil containing $2.5 \mathrm{~g} / \mathrm{L}$ agarose for $72 \mathrm{~h}$. The fermentation products were analyzed using TLC and HPLC. NeoDP4 production was confirmed using TLC analysis (Fig. 4A). The initially added glucose was confirmed to be depleted after $36 \mathrm{~h}$. Based on HPLC analysis of the fermentation products at each time point, $1.86 \mathrm{~g} / \mathrm{L}$ NeoDP4 was obtained after $72 \mathrm{~h}$ of fermentation (Fig. 4B). Cell growth entered the stationary phase from $24 \mathrm{~h}$ onwards and reached an $\mathrm{OD}_{600}=6.7$. Both ethanol and acetic acid accumulated up to a concentration of $4.8 \mathrm{~g} / \mathrm{L}$. In conclusion, NeoDP4 was produced as the target major product by the engineered yeast SB-HTU_16A_D. 


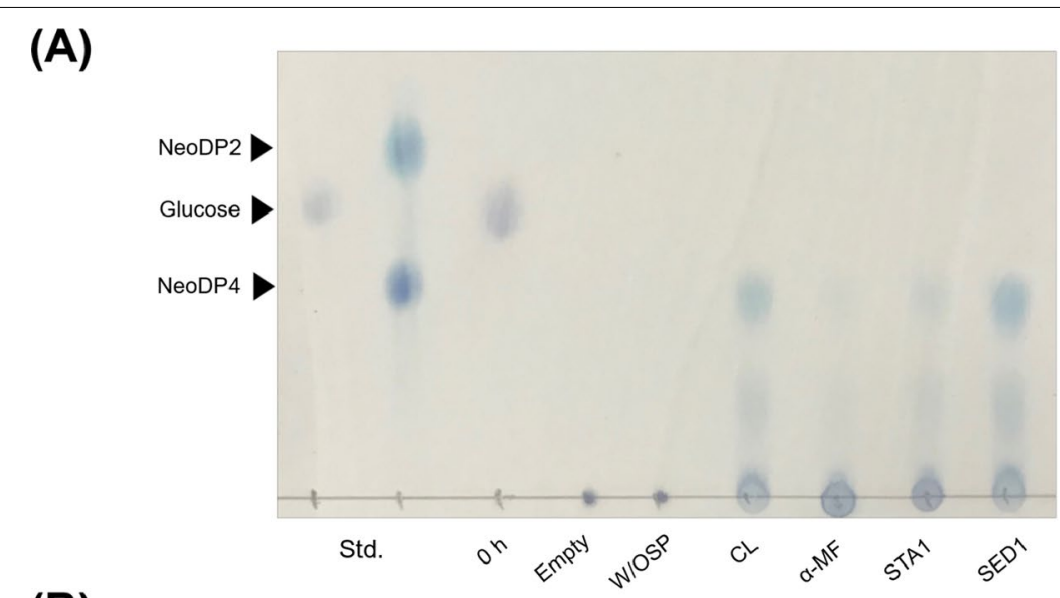

(B)

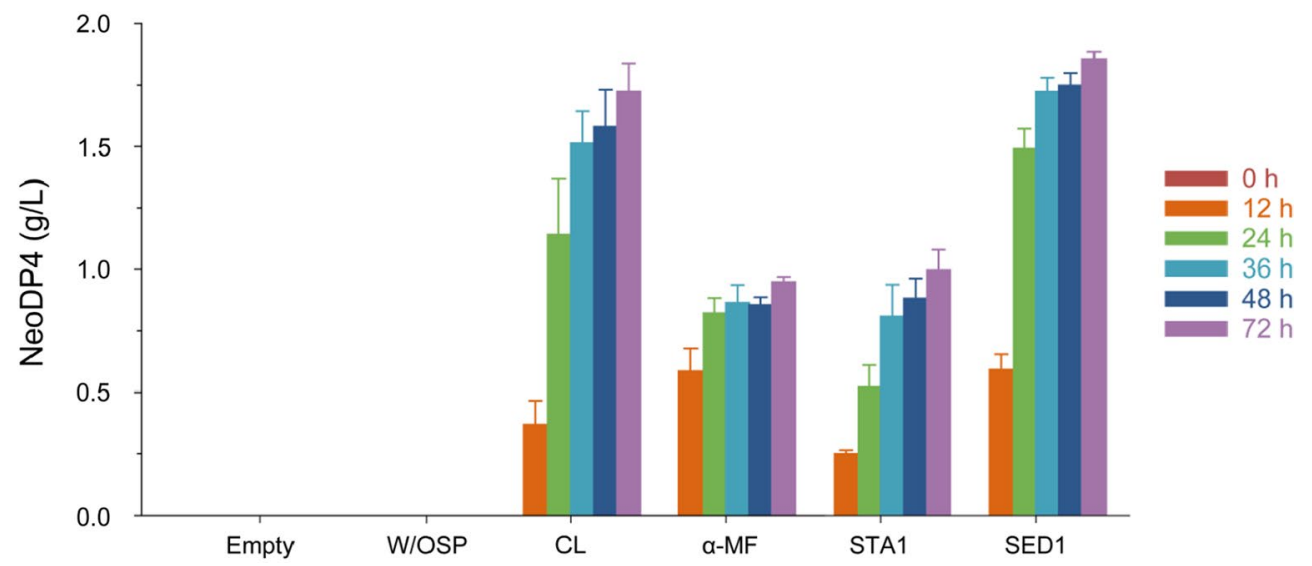

Fig. 3 Signal peptide screening for the production of NeoDP4 in S. boulardii. A TLC analysis of the fermentation products by engineered yeast strains. B Comparison of the extracellular NeoDP4 concentration depending on the origin of the signal peptide sequences. Empty, SB-HTU_16A_E harboring pRS426GPD;W/OSP, SB-HTU_16A_W harboring p426_Bp_W/OSP; CL, SB-HTU_16A_C harboring p426_BP_CL; a-MF, SB-HTU_16A_A harboring p426_Bp_aMF; STA1, SB-HTU_16A_S harboring p426_Bp_STA1; SED1, SB-HTU_16A_D harboring p426_Bp_SED1. Engineered strains were cultured with $20 \mathrm{~g} / \mathrm{L}$ glucose and $2.5 \mathrm{~g} / \mathrm{L}$ agarose in $50 \mathrm{mM} \mathrm{KHP}$ buffer $(\mathrm{pH} 5.5)$ at $37^{\circ} \mathrm{C}$ and $200 \mathrm{rpm}$ for $72 \mathrm{~h}$. Results are presented as the mean values and standard deviations of data from three independent biological replicates. NeoDP4, neoagarotetraose; NeoDP2, neoagarobiose

\section{Strain construction using CRISPR-Cas9 and fermentation} For stable expression, BpGH16A and SED1 were introduced into the genome of $S$. boulardii, in this study. $B p$ GH16A gene knock-in was performed via homologous recombination using CRISPR-Cas9 (Additional file 1: Fig. S1A). After yeast transformation, the gene encoding $B p$ GH16A was confirmed to have entered the genome successfully, using yeast colony PCR. Primer pairs Conf-CS5-F and Conf-CS5-R were designed and used so that the size was $2.4-\mathrm{kb}$ when the gene entered and $0.5-\mathrm{kb}$ when the gene was not entered (Table 2). The successful integration of $B p$ GH16A and SED1 into S. boulardii was confirmed with yeast colony PCR, based on the formation of a 2.4-kb single band in 3 lanes, namely, 4, 7, and 8 out of total 9 lanes (Additional file 1: Fig. S1B).

Finally, strain SB_16A_D containing BpGH16A and SED1 in the $S$. boulardii genome was constructed using
CRISPR-Cas9, and flask fermentation proceeded in YSC medium containing $2.5 \mathrm{~g} / \mathrm{L}$ agarose, for $72 \mathrm{~h}$. NeoDP4 production was confirmed using TLC analysis (Fig. 5A), suggesting that $B p \mathrm{GH} 16 \mathrm{~A}$ was secreted from strain SB_16A_D. For more accurate fermentation products analysis, HPLC analysis and growth measurement were performed at each time point as well (Fig. 5B). Glucose was depleted before $12 \mathrm{~h}$ of fermentation had passed, and the strain grew to an $\mathrm{OD}_{600}=15.51$ at $72 \mathrm{~h}$. After fermentation, $0.80 \mathrm{~g} / \mathrm{L}$ NeoDP4 was produced, as well as $3.03 \mathrm{~g} / \mathrm{L}$ ethanol and $3.65 \mathrm{~g} / \mathrm{L}$ acetic acid.

\section{Discussion}

S. boulardii has been widely used as a probiotic because it can compete with diarrhea-causing pathogens in the human gut [39]. Additionally, S. boulardii may be 


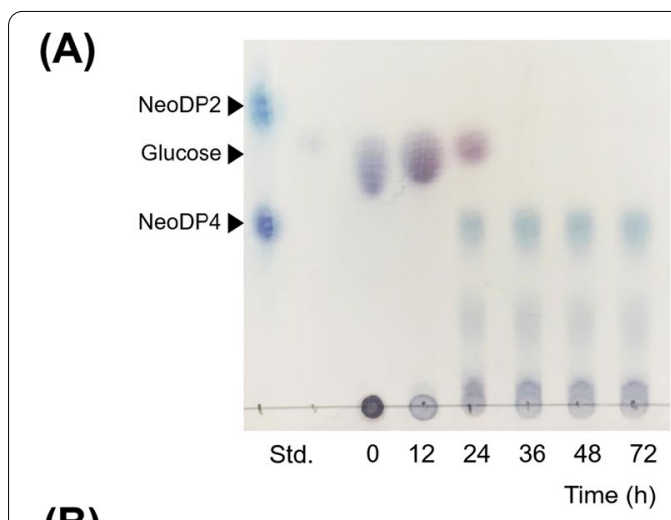

(B)

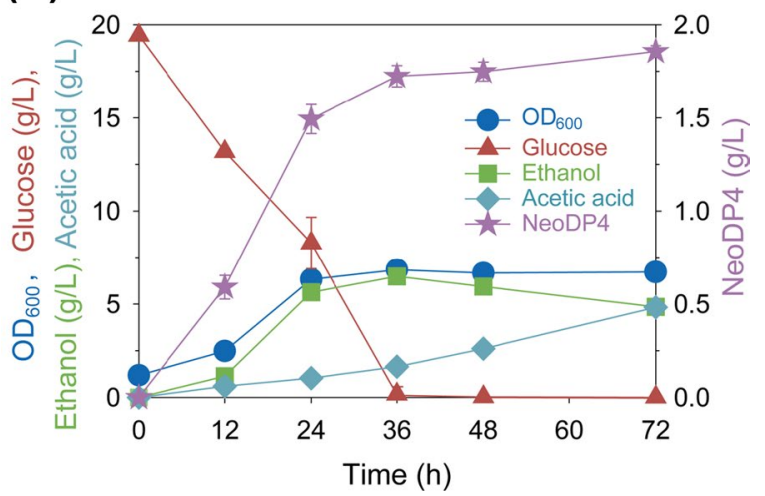

Fig. 4 Fermentation profiles of engineered S. boulardii SB-HTU_16A_D harboring p426_BP_SED1. A Time course analysis of the fermentation products of SB-HTU_16A_D using TLC. B Fermentation profiles of engineered S. boulardii SB-HTU_16A_D in YSC medium containing $20 \mathrm{~g} / \mathrm{L}$ glucose and $2.5 \mathrm{~g} / \mathrm{L}$ agarose in $50 \mathrm{mM} \mathrm{KHP}$ buffer (pH 5.5) at $37^{\circ} \mathrm{C}$ and $200 \mathrm{rpm}$ for $72 \mathrm{~h}$. During fermentation, the cell density $\left(\mathrm{OD}_{600}\right)$ and the concentration values of glucose, ethanol, acetic acid, and NeoDP4 were monitored using HPLC. All data points are the means of experimental data from triplicate fermentations. SB-HTU_16A_D harboring p426_BP_SED1. NeoDP4, neoagarotetraose; NeoDP2, neoagarobiose; YSC, yeast synthetic complete

used as a host for a microbial cell factory that produces useful proteins in the gut [11]. S. boulardii has been metabolically engineered; however, it has not yet been engineered to produce prebiotics [17]. In this study, we introduced an endo-type $\beta$-agarase, $B p$ GH16A, into $S$. boulardii to produce potential prebiotics, NAOSs from red macroalgal agarose (Fig. 1). The production of NeoDP4, a NAOS, was verified by engineered $S$. boulardii.

NAOSs, which can be produced by hydrolyzing agarose extracted from red macroalgae by endo-type $\beta$-agarase, have been reported to possess various health benefits [22-27]. NeoDP4, which is a representative NAOS, has been reported to have various biological properties [40,41]. For example, the anti-fatigue

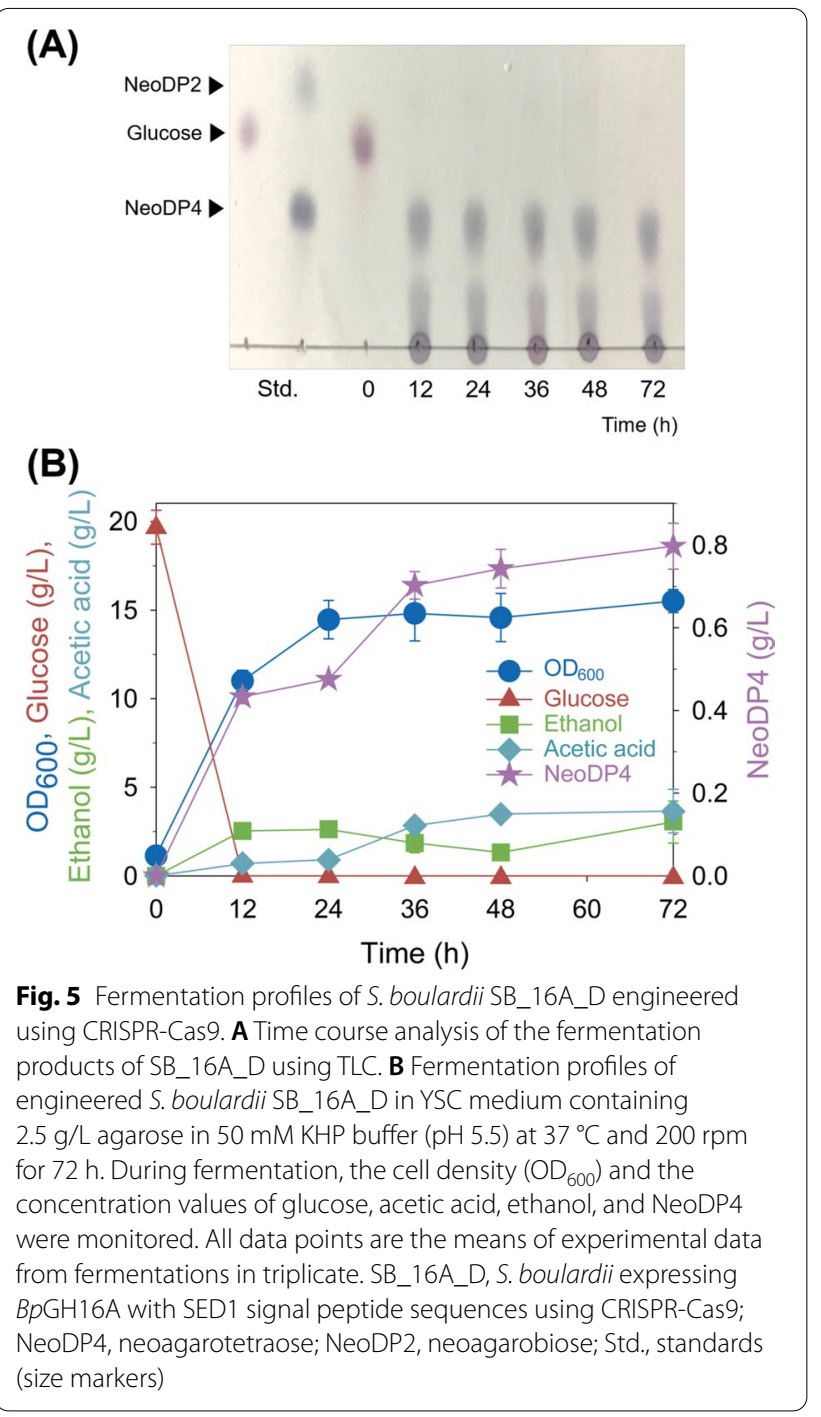

effects of NeoDP4 via short-chain fatty acid production and regulation of the microbial composition have been demonstrated in mice [29]. Moreover, a significant increase in Lactobacillus and Bifidobacterium was observed by supplementing mice with NeoDP4, implying that NeoDP4 is a potential prebiotic [29]. NeoDP4 is also known to alleviate the inflammatory response by inhibiting the MAPK and NF- $\mathrm{kB}$ signaling pathways [26]. Therefore, the requirement for production of NAOSs, especially NeoDP4, is increasing rapidly [42].

One of the goals of this study was to effectively secrete $B p \mathrm{GH} 16 \mathrm{~A}$ to hydrolyze agarose into NeoDP4 by expressing a signal peptide in engineered yeast. Previous studies have used CL or $\alpha-M F$ signal peptides to secrete proteins from S. boulardii $[11,16,17]$. Based on additional screening using STA1 and SED1 used in other yeast strains $[36,37]$, all of them (CL, $\alpha-M F$, STA1, and SED1) were 
confirmed to secrete BpGH16A in S. boulardii (Fig. 3). Through signal peptide screening, SED1 was shown to have the highest efficiency in producing NeoDP4 via secretion of $B p \mathrm{GH} 16 \mathrm{~A}$. Because of the lack of other reports on signal peptide screening in S. boulardii so far, this study could contribute to studies on the production and secretion of other proteins by S. boulardii.

Genomic integration can avoid problems that may arise in a complex intestinal environment when using plasmids. These problems include plasmid instability in the absence of selective pressure, potential diffusion to other microorganisms, and an increased metabolic burden associated with the maintenance of multicopy plasmids [43]. Therefore, we attempted to integrate BACPLE_01670 coding for BpGH16A into the genome of $S$. boulardii using the CRISPR-Cas9 system, which is a sophisticated and advanced genomic engineering tool (Additional file 1: Fig. S1A) [44], and succeeded in constructing an $S$. boulardii strain that secretes $B p \mathrm{GH} 16 \mathrm{~A}$, namely, SB_16A_D. SB_16A_D strain produced $0.80 \mathrm{~g} / \mathrm{L}$ NeoDP4 (Fig. 5) at $72 \mathrm{~h}$. Compared to that when using a plasmid vector system with an auxotrophic marker, the final $\mathrm{OD}_{600}$ after $72 \mathrm{~h}$ of fermentation of the strain constructed using the CRISPR-Cas9 system was 2.3 times higher, but the NeoDP4 production was lower. This difference was presumed to be due to the relatively strong constitutive promoter and the high copy number of the pRS426GPD plasmid [45]. Nevertheless, the successful protein secretion from $S$. boulardii using genomic integration showed that $S$. boulardii could be used as a microbial cell factory for producing useful proteins and their products in the human gut.

\section{Conclusions}

We have, for the first time, demonstrated that NAOSs can be produced by the probiotic yeast $S$. boulardii. Our signal peptide screening results provide more options available in $S$. boulardii. We also succeeded in producing health beneficial substances using probiotic yeast harboring $B p \mathrm{GH} 16 \mathrm{~A}$, an endo-type $\beta$-agarase, originating from the human gut bacteria $B$. plebeius. Our results suggest that synbiotics can be achieved by engineered probiotic yeast that produce prebiotics in the human gut.

\section{Abbreviations}

a-MF: a-Mating factor signal peptide; CL: Chicken lysozyme signal peptide; CRISPR: Clustered regularly interspaced short palindromic repeat; GH16: Glycoside hydrolase 16; GRAS: Generally regarded as safe; HPLC: High-performance liquid chromatography; KHP: Potassium hydrogen phthalate; NAOSs: Neoagarooligosaccharides; NAT: Nourseothricin; NeoDP4: Neoagarotetraose; $\mathrm{OD}_{600}$ : Optical density at 600 nm; PCR: Polymerase chain reaction; PEG: Polyethylene glycol; RI: Refractive index; SED1: SED1 Signal peptide; STA1: STA1 Signal peptide; TLC: Thin-layer chromatography; YSC:Yeast synthetic complete.

\section{Supplementary Information}

The online version contains supplementary material available at https://doi. org/10.1186/s12934-021-01644-w.

Additional file 1: Fig. S1. Engineering of S. boulardii for NAOSs production using CRISPR-Cas9 system. (A) Diagram for the construction of engineered S. boulardii expressing BpGH16A using the CRISPR-Cas9 system.

(B) Yeast colony PCR for confirmation of the genomic integration of each mutant.

\section{Acknowledgements}

Facility support from the Institute of Biomedical Science and Food Safety at the Korea University Food Safety Hall is acknowledged.

\section{Authors' contributions \\ YJ and SY designed and performed the experiments, analyzed the data, and wrote the manuscript. JW, JJL, and EJY performed the experiments, analyzed the data, and wrote the manuscript. YSJ and KHK conceived the project, designed the experiments, analyzed the data, and wrote the manuscript. All authors read and approved the final manuscript.}

\section{Funding}

This work was supported by the Mid-career Researcher Program (2020R1A2B5B02002631) through the National Research Foundation of Korea (NRF), the Ministry of Oceans and Fisheries, Korea (20200367), and the Korea Institute of Planning and Evaluation for Technology in Food, Agriculture, Forestry, and Fisheries, funded by the Ministry of Agriculture, Food, and Rural Affairs (321036051SB010). This research was also funded by National Institute of Food and Agriculture, U.S. Department of Agriculture: ILLU-698-914 awarded to YSJ and DNS Vision 20/20 awarded to EJY and YSJ.

\section{Availability of data and materials}

The datasets used and/or analyzed during the current study are available from the corresponding authors upon reasonable request.

\section{Declarations}

Ethics approval and consent to participate Not applicable.

Consent for publication

Not applicable.

Competing interests

The authors declare that they have no competing interests.

\section{Author details}

1Department of Biotechnology, Graduate School, Korea University, Seoul 02841, South Korea. ${ }^{2}$ Carl R. Woese Institute for Genomic Biology, University of Illinois at Urbana-Champaign, Urbana, IL 61801, USA. ${ }^{3}$ Department of Food Science and Human Nutrition, University of Illinois at UrbanaChampaign, Urbana, IL 61801, USA.

Received: 25 February 2021 Accepted: 23 July 2021

Published online: 18 August 2021

\section{References}

1. Clemente JC, Ursell LK, Parfrey LW, Knight R. The impact of the gut microbiota on human health: an integrative view. Cell. 2012;148:1258-70.

2. Zheng D, Liwinski T, Elinav E. Interaction between microbiota and immunity in health and disease. Cell Res. 2020;30:492-506.

3. Ferrer-Miralles N, Domingo-Espín J, Corchero JL, Vázquez E, Villaverde A. Microbial factories for recombinant pharmaceuticals. Microb Cell Fact. 2009;8:17.

4. Schmidt F. Recombinant expression systems in the pharmaceutical industry. Appl Microbiol Biotechnol. 2004;65:363-72. 
5. Rangel AE, Gómez Ramírez JM, González Barrios AF. From industrial by-products to value-added compounds: the design of efficient microbial cell factories by coupling systems metabolic engineering and bioprocesses. Biofuel Bioprod Biorefin. 2020;14:1228-38.

6. Marteau P, Vesa T. Pharmacokinetics of probiotics and biotherapeutic agents in humans. Biosci Microflora. 1998;17:1-6.

7. Blehaut H, Massot J, Elmer G, Levy R. Disposition kinetics of Saccharomyces boulardii in man and rat. Biopharm Drug Dispos. 1989;10:353-64.

8. Elmer G, McFarland L, Surawicz C, Danko L, Greenberg R. Behaviour of Saccharomyces boulardii in recurrent Clostridium difficile disease patients. Aliment Pharmacol Ther. 1999;13:1663-8.

9. Jenkins N. Modifications of therapeutic proteins: challenges and prospects. Cytotechnology. 2007:53:121-5.

10. Al-zaidi RE, Al-Mozan HD, Alrikabi NJ. Eukaryotic probiotic Saccharomyces boulardii application in clinical trails: a review. Int J Pharm Qual Assur. 2020;11:160-5.

11. Li R, Wan X, Takala TM, Saris PE. Heterologous expression of the leuconostoc bacteriocin Leucocin C in probiotic yeast Saccharomyces boulardii. Probiotics Antimicrob Proteins. 2021;13:229-37.

12. van der Aa Kühle $A$, Jespersen $L$. The taxonomic position of Saccharomyces boulardii as evaluated by sequence analysis of the D1/D2 domain of $26 \mathrm{~S}$ rDNA, the ITS1-5.8 S rDNA-ITS2 region and the mitochondrial cytochrome-c oxidase II gene. Syst Appl Microbiol. 2003;26:564-71.

13. Douradinha B, Reis VC, Rogers MB, Torres FA, Evans JD, Marques ET Jr. Novel insights in genetic transformation of the probiotic yeast Saccharomyces boulardii. Bioengineered. 2014;5:21-9.

14. Czerucka D, Piche T, Rampal P. Review article: yeast as probiotics-Saccharomyces boulardii. Aliment Pharmacol Ther. 2007;26:767-78.

15. Kotowska M, Albrecht P, Szajewska H. Saccharomyces boulardii in the prevention of antibiotic-associated diarrhoea in children: a randomized double-blind placebo-controlled trial. Aliment Pharmacol Ther. 2005;21:583-90.

16. Bagherpour G, Ghasemi H, Zand B, Zarei N, Roohvand F, Ardakani EM, Azizi M, Khalaj V. Oral administration of recombinant Saccharomyces boulardii expressing ovalbumin-CPE fusion protein induces antibody response in mice. Front Microbiol. 2018;9:723.

17. Liu J-J, Kong II, Zhang G-C, Jayakody LN, Kim H, Xia P-F, Kwak S, Sung BH, Sohn J-H, Walukiewicz HE. Metabolic engineering of probiotic Saccharomyces boulardii. Appl Environ Microbiol. 2016;82:2280-7.

18. Gibson GR, Roberfroid MB. Dietary modulation of the human colonic microbiota: introducing the concept of prebiotics. J Nutr. 1995;125:1401-12.

19. Pistollato F, Sumalla Cano S, Elio I, Masias Vergara M, Giampieri F, Battino M. Role of gut microbiota and nutrients in amyloid formation and pathogenesis of Alzheimer disease. Nutr Rev. 2016;74:624-34.

20. Sonnenburg ED, Sonnenburg JL. Starving our microbial self: the deleterious consequences of a diet deficient in microbiota-accessible carbohydrates. Cell Metab. 2014;20:779-86.

21. Kolb N, Vallorani L, Milanović N, Stocchi V. Evaluation of marine algae wakame (Undaria pinnatifida) and kombu (Laminaria digitata japonica) as food supplements. Food Technol Biotechnol. 2004;42:57-61.

22. Torres MD, Flórez-Fernández N, Domínguez H. Integral utilization of red seaweed for bioactive production. Mar Drugs. 2019;17:314.

23. Hong SJ, Lee J-H, Kim EJ, Yang HJ, Park J-S, Hong S-K. Anti-obesity and anti-diabetic effect of neoagarooligosaccharides on high-fat dietinduced obesity in mice. Mar Drugs. 2017;15:90.

24. Lee MH, Jang J-H, Yoon GY, Lee SJ, Lee M-G, Kang TH, Han HD, Kim HS, Choi WS, Park WS. Neoagarohexaose-mediated activation of dendritic cells via Toll-like receptor 4 leads to stimulation of natural killer cells and enhancement of antitumor immunity. BMB Rep. 2017;50:263.

25. Lin F, Yang D, Huang Y, Zhao Y, Ye J, Xiao M. The potential of neoagarooligosaccharides as a treatment of type II diabetes in mice. Mar Drugs. 2019;17:541.

26. Wang W, Liu P, Hao C, Wu L, Wan W, Mao X. Neoagaro-oligosaccharide monomers inhibit inflammation in LPS-stimulated macrophages through suppression of MAPK and NF-kB pathways. Sci Rep. 2017;7:44252.

27. Kim M, Lee J-E, Cho H, Jung H-G, Lee W, Seo HY, Lee S-H, Ahn D-G, Kim S-J, Yu J-W. Antiviral efficacy of orally delivered neoagarohexaose, a nonconventional TLR4 agonist, against norovirus infection in mice. Biomaterials. 2020;263:120391.

28. Hu B, Gong Q, Wang Y, Ma Y, Li J, Yu W. Prebiotic effects of neoagarooligosaccharides prepared by enzymatic hydrolysis of agarose. Anaerobe. 2006;12:260-6

29. Zhang N, Hou E, Song J, Li J, Tang Q, Mao X. Neoagarotetraose-modulated gut microbiota and alleviated gut inflammation in antibiotic treatment mice. Food Agric Immunol. 2017;28:1408-23.

30. Xu X-Q, Su B-M, Xie J-S, Li R-K, Yang J, Lin J, Ye X-Y. Preparation of bioactive neoagaroligosaccharides through hydrolysis of Gracilaria lemaneiformis agar: a comparative study. Food Chem. 2018;240:330-7.

31. Kailasapathy K, Chin J. Survival and therapeutic potential of probiotic organisms with reference to Lactobacillus acidophilus and Bifidobacterium spp. Immunol Cell Biol. 2000;78:80-8.

32. Hehemann J-H, Kelly AG, Pudlo NA, Martens EC, Boraston AB. Bacteria of the human gut microbiome catabolize red seaweed glycans with carbohydrate-active enzyme updates from extrinsic microbes. Proc Natl Acad Sci U S A. 2012;109:19786-91.

33. Hehemann J-H, Correc G, Barbeyron T, Helbert W, Czjzek M, Michel G. Transfer of carbohydrate-active enzymes from marine bacteria to Japanese gut microbiota. Nature. 2010;464:908-12.

34. Zhang G-C, Kong II, Kim H, Liu J-J, Cate JH, Jin Y-S. Construction of a quadruple auxotrophic mutant of an industrial polyploid Saccharomyces cerevisiae strain by using RNA-guided Cas9 nuclease. Appl Environ Microbiol. 2014;80:7694-701.

35. Gietz RD, Schiestl RH, Willems AR, Woods RA. Studies on the transformation of intact yeast cells by the LiAc/SS-DNA/PEG procedure. Yeast. 1995; 11:355-60.

36. Inokuma K, Bamba T, Ishii J, Ito Y, Hasunuma T, Kondo A. Enhanced cell-surface display and secretory production of cellulolytic enzymes with Saccharomyces cerevisiae Sed1 signal peptide. Biotechnol Bioeng. 2016;113:2358-66.

37. Yanagisawa M, Kasuu M, Ariga O, Nakasaki K. Direct production of ethanol from neoagarobiose using recombinant yeast that secretes a-neoagarooligosaccharide hydrolase. Enzyme Microb Technol. 2016:85:82-9.

38. Yun EJ, Lee S, Kim JH, Kim BB, Kim HT, Lee SH, Pelton JG, Kang NJ, Choi I-G, Kim KH. Enzymatic production of 3,6-anhydro-L-galactose from agarose and its purification and in vitro skin whitening and anti-inflammatory activities. Appl Microbiol Biotechnol. 2013;97:2961-70.

39. Micklefield G. Saccharomyces boulardii in the treatment and prevention of antibiotic-associated diarrhea. MMW Fortschr Med. 2014;156:61.

40. Hong SJ, Lee J-H, Kim EJ, Yang HJ, Chang Y-K, Park J-S, Hong S-K. In vitro and in vivo investigation for biological activities of neoagarooligosaccharides prepared by hydrolyzing agar with $\beta$-agarase. Biotechnol Bioprocess Eng. 2017;22:489-96.

41. Fu XT, Kim SM. Agarase: review of major sources, categories, purification method, enzyme characteristics and applications. Mar Drugs. 2010;8:200-18.

42. Koti BA, Shinde M, Lalitha J. Repeated batch production of agar-oligosaccharides from agarose by an amberlite IRA-900 immobilized agarase system. Biotechnol Bioprocess Eng. 2013;18:333-41.

43. Durmusoglu D, Al'Abri IS, Collins SP, Beisel C, Crook NC. Establishing probiotic Saccharomyces boulardii as a model organism for synthesis and delivery of biomolecules. bioRxiv. 2020.01.22.915389.

44. Doudna JA, Charpentier E. The new frontier of genome engineering with CRISPR-Cas9. Science. 2014;346:1258096.

45. Mumberg D, Müller R, Funk M. Yeast vectors for the controlled expression of heterologous proteins in different genetic backgrounds. Gene. 1995;156:119-22.

46. Taxis C, Knop M. System of centromeric, episomal, and integrative vectors based on drug resistance markers for Saccharomyces cerevisiae. Biotechniques. 2006;40:73-8.

\section{Publisher's Note}

Springer Nature remains neutral with regard to jurisdictional claims in published maps and institutional affiliations. 